\title{
Relationship of photosynthesis and related traits to seed yield in oilseed Brassicas
}

\author{
Pushp Sharma \\ Department of Plant Breeding and Genetics, Punjab Agricultural University, Ludhiana-141004 (Punjab), INDIA \\ E- mail: pushp20@yahoo.com \\ Received: March 8. 2015; Revised received: August 30, 2015; Accepted: October 23, 2015
}

\begin{abstract}
The physiological basis of yield in oilseeds Brassicas needs to be investigated, and the contribution of these traits to its yield is difficult to decipher. Eight cultivars of Brassica belonging to 3 species viz. B. juncea, $B$. napus and $B$. carinata - based on significant differences in yield were tested over two years. Net photosynthesis, transpiration, stomatal conductance and water use efficiency were investigated on $3^{\text {rd }}$ and $4^{\text {th }}$ fully expanded leaf on the main stem and related to yield. Average photosynthetic efficiency (umolm ${ }^{-2} \mathrm{~s}^{-1}$ ) was higher in RLC1 (36.1), GSC6 (36.3) and PC5 (33.8) cultivars. Impact of environment was inconspicuous. However interactions (GxY) were significant for the studied photosynthetic traits except $\mathrm{Pn}$. Lower transpiration rates were associated with higher water use efficiency in RLC1 (5.69), GSL1 (5.44) and GSC6 (5.40). Positive correlation between SY and Pn (0.385) was recorded for the first time in Brassicas although the magnitude of association was low. Quality mustard cultivar (RLC1, B. juncea) and amongst B. napus GSC6 (canola) and Hyola PAC401 (hybrid, canola) were higher yielders due to relative high $\mathrm{Pn}$, more efficient utilization of water and chlorophyll content. Indeterminate growth habits of the cultivars indicated highest contribution to $\mathrm{Pn}$ by leaves during flowering as compared with early siliquae formation. Environment had a profound impact on the yielding ability and the photosynthetic traits.
\end{abstract}

Keywords: Brassicas, Chlorophyll, Photosynthesis, Yield

\section{INTRODUCTION}

Rapeseed and mustard (Brassicas spp.) is the second important oilseed crop of the country after soybean and plays significant role in Indian oil economy by contributing about $27 \%$ to the total oilseed production. A major breeding objective for oilseeds is yield improvement. An increased understanding of the physiological basis for seed yield could enhance utilization of physiological traits as selection criteria for yield improvement (Chongo and McVetty 2001). Photosynthesis, a major determinant for total dry matter production in a crop species, has often been related to seed yield of crop plants with a view of selecting plants with high net photosynthesis (Pn) to improve yield. For high yield, a significant portion of the dry matter produced should be partitioned into the harvestable component. Cultivars could be improved if selection was directed towards genotypes with high yield potentials and high Pn rates, but with constant Tr. However, correlations between yield and leaf $\mathrm{Pn}$ rate are rare, even though photosynthesis is the source of total dry matter production (Lawlor, 1995). In soybean (Gylcine max.L.) cultivars, high yields were associated with high leaf Pn but no genetic differences were found in $\mathrm{Pn}$ in wheat (Triticum aestivum L.) or its relatives, while the relationship between Pn per unit leaf area and seed yield was poor in barely (Hordeun vulgare L), pea
(Pisum sativum L.) and Brassica napus (Chongo and McVetty, 2001).The lack of correlation between photosynthesis and yield has been attributed to measuring photosynthetic rates on single leaves for a short period time, which does not adequately represent seasonal canopy photosynthesis or the total sink and photosynthetic capacity per unit leaf area (Richards, 2000; Kumar and Chopra, 2014). Leaves are the source of photosynthesis in Brassicas, though they senesce rapidly during siliquae development. Leaves establish the sink potential via structures such as number of siliquae/plant or number of seeds/siliqua and remobilization of photosynthates during their senescence, but eventually stems and siliquae became important sources of photosynthesis (Uddin et al., 2012). Photosynthesis partly depends on water and chlorophyll during assimilation, which is important for seed yield. Pn was associated with other physiological traits as they relate to yield and holds importance for yield improvement in oilseed crops. The objective of this study was to measure net photosynthetic rates (Pn), transpiration (Tr), stomatal conductance (Cs), water use efficiency in eight oilseed popular and recommended varieties and relate them to seed yield.

\section{MATERIALS AND METHODS}

Experimental procedure: Field experiments were conducted during two (Rabi) winter seasons in the farm 
Table 1. Mean monthly meteorological summaries at PAU in 2011-12 and 2012-13.

\begin{tabular}{|c|c|c|c|c|c|c|}
\hline Crop season & $\begin{array}{l}\text { Tempera- } \\
\text { ture }\left({ }^{\circ} \mathrm{C}\right)\end{array}$ & $\begin{array}{c}\text { Relative } \\
\text { humidity (\%) } \\
\end{array}$ & $\begin{array}{c}\text { Rainfall } \\
(\mathrm{mm})\end{array}$ & $\begin{array}{c}\text { Number } \\
\text { of rainy days }\end{array}$ & $\begin{array}{c}\text { Total evaporation } \\
(\mathrm{mm})\end{array}$ & $\begin{array}{c}\text { Sunshine } \\
\text { (hrs) }\end{array}$ \\
\hline \multicolumn{7}{|l|}{ 2011-12 } \\
\hline November & 19.1 & 71 & - & - & 13.5 & 4.5 \\
\hline December & 13.9 & 72.7 & 11.4 & 2 & 9.8 & 6.7 \\
\hline January & 11.8 & 77.8 & 52.6 & 4 & 2.9 & 6.9 \\
\hline February & 13.8 & 68.5 & 1.2 & Light shower & 19.8 & 7.2 \\
\hline March & 19.9 & 61.2 & - & - & 31.6 & 7.8 \\
\hline $1^{\text {st }}$ week of April & 26.9 & 54 & - & - & 39.8 & 9.3 \\
\hline \multicolumn{7}{|l|}{ 2012-13 } \\
\hline November & 17.8 & 65.5 & - & - & 13.6 & 7.1 \\
\hline December & 13.4 & 75.2 & 17.4 & 2 & 11.2 & 6.3 \\
\hline January & 11.6 & 77.4 & 30.8 & 3 & 10.3 & 4.8 \\
\hline February & 15.2 & 81.8 & 71.8 & 6 & 14.8 & 7.6 \\
\hline March & 21.0 & 71.3 & 35.6 & 2 & 26.6 & 9.1 \\
\hline $1^{\text {st }}$ week of April & 23.6 & 53.0 & - & - & 45.5 & 11.1 \\
\hline
\end{tabular}

of oilseeds Section, Department of Plant Breeding and Genetics, Punjab Agricultural University (PAU), Ludhiana. Trails were laid in randomized complete block design (RCBD) with three replications. Eight oilseed cultivars, currently recommended for production in Punjab, ranked for seed yield belonging to 3 species viz. B.juncea [Indian mustard, PBR210, PBR91, RLC1 (quality)], B.napus [Gobhi sarson GSL1 (non-canola), GSC6, GSC5 (canola), HyolaPAC401 (hybrid, canola)] and B.carinata (African sarson, PC5) were used in the study. Sowing was done on $11^{\text {th }}$ November 2011 and $1^{\text {st }}$ November in $2012.1 .5 \mathrm{~kg}$ seed per acre was used for rapeseed-mustard and seeding was done with a drill at $4-5 \mathrm{~cm}$ depth. Each variety consisted of 5 rows of $3 \mathrm{~m}$ row length . Row to row and
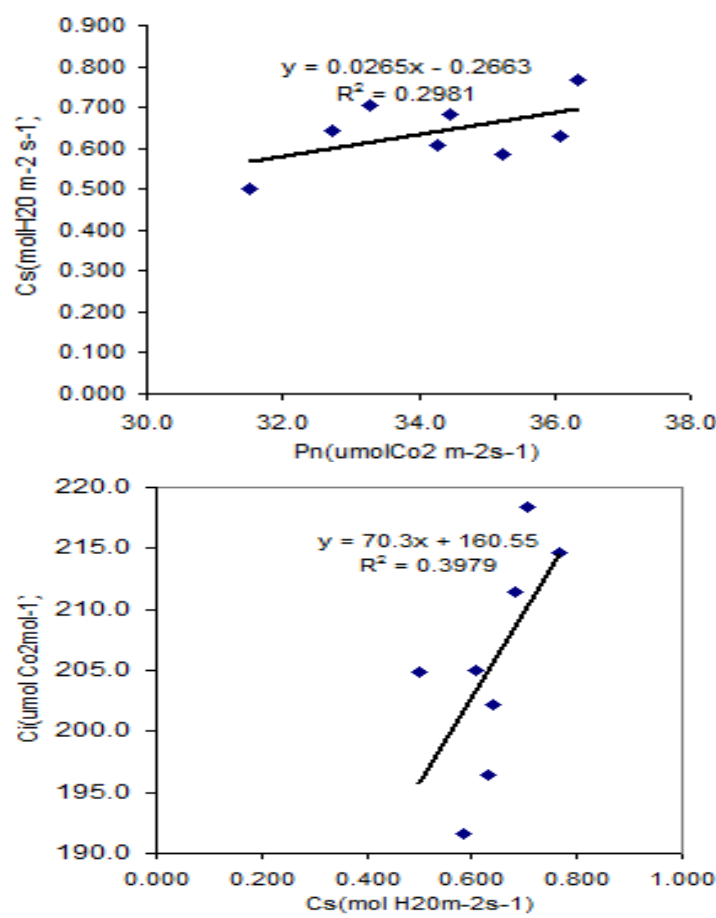

plant to plant distance was $30 \times 10 \mathrm{~cm}$ for $B$.juncea and B.carinata while $45 \times 10 \mathrm{~cm}$ for B.napus. Thinning was done three weeks after sowing to maintain plant to plant distance as per requirement. All the recommended agronomic and protection practices were followed to raise a healthy crop Three plants per replication were randomly tagged to measure photosynthetic rates. Seasonal weather data has been recorded (Table 1). Rainfall of $65.2 \mathrm{~mm}$ in 6 days during 2011-12 and $155.6 \mathrm{~mm}$ rainfall in 13 days during 2012-13 in comparison to $101.6 \mathrm{~mm}$ of normal rainfall during same period at PAU. Rainfall was above average during $2^{\text {nd }}$ crop season.

Gas exchange measurements: Gas exchange measurements were done using a portable photosynthesis
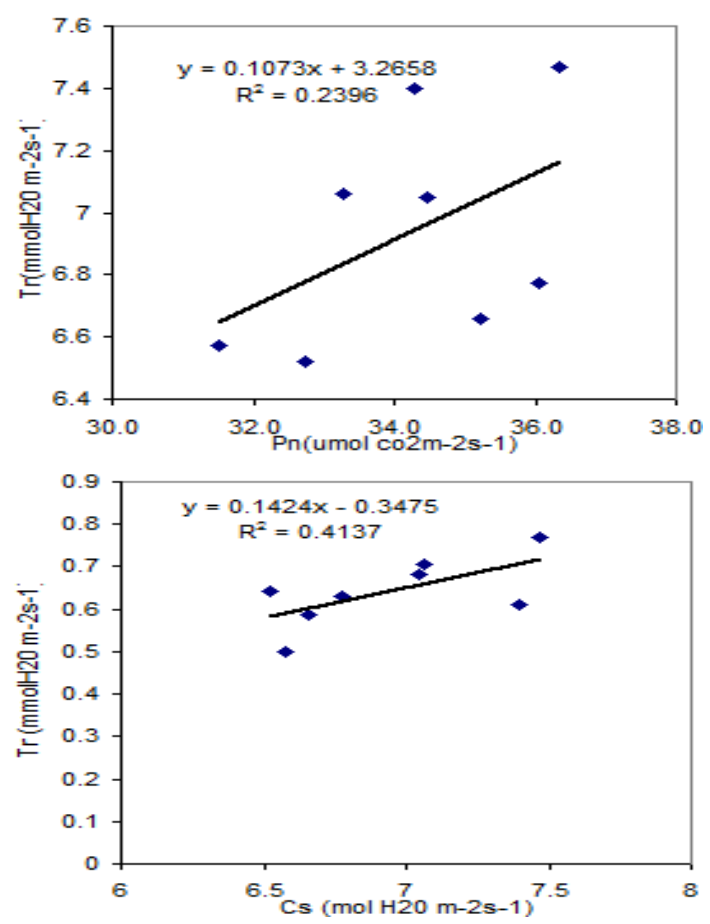

Fig. 1. Relationship between different components of photosynthesis. 
Pushp Sharma / J. Appl. \& Nat. Sci. 7 (2): 851 - 856 (2015)
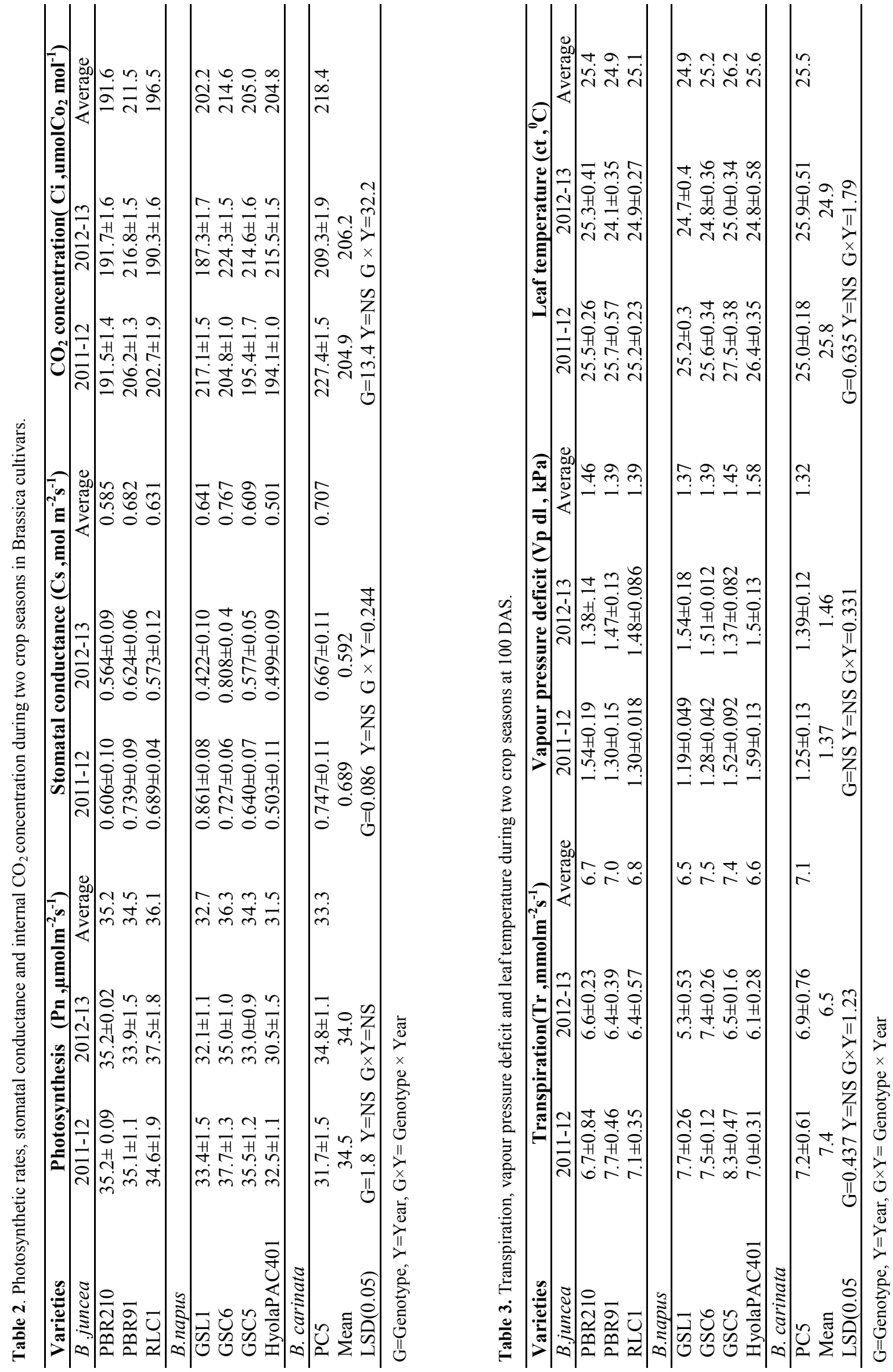
Table 4. Water use efficiency at 100 DAS in Brassica cultivars.

\begin{tabular}{lccc}
\hline Varieties & \multicolumn{3}{c}{$\begin{array}{c}\text { Water use efficiency } \\
\text { (WUE, } \boldsymbol{\mu} \text { mol/mmol) }\end{array}$} \\
\hline B.juncea & $2011-12$ & $2012-13$ & Average \\
\hline PBR210 & $5.81 \pm 0.28$ & $5.47 \pm 0.14$ & 5.64 \\
PBR91 & $5.23 \pm 0.16$ & $5.62 \pm 0.18$ & 5.43 \\
RLC1 & $5.23 \pm 0.09$ & $6.15 \pm 0.18$ & 5.69 \\
\hline B.napus & & & \\
\hline GSL1 & $4.84 \pm 0.22$ & $6.03 \pm 0.25$ & 5.44 \\
GSC6 & $5.60 \pm 0.15$ & $5.19 \pm 0.09$ & 5.40 \\
GSC5 & $4.99 \pm 0.13$ & $5.33 \pm 0.1$ & 5.16 \\
HyolaPAC401 & $5.24 \pm 0.15$ & $5.18 \pm 0.07$ & 5.21 \\
\hline B.carinata & \multicolumn{4}{|}{} \\
\hline PC5 & $4.90 \pm 0.18$ & $5.33 \pm 0.09$ & 5.12 \\
Mean & 5.23 & 5.54 & \\
LSD(0.05) & $\mathrm{G}=0.157$ & $\mathrm{Y}=0.314$ & $\mathrm{G} \times \mathrm{Y}=0.449$ \\
\hline G-Ger
\end{tabular}

$\mathrm{G}=$ Genotype, $\mathrm{Y}=$ Year, $\mathrm{G} \times \mathrm{Y}=$ Genotype $\times$ Year

system with an infra red gas analyzer in a closed system with 1-L chamber (Model LI -6200, Licor, Inc., Lincoln, NE). The measurements were conducted in the morning between $11 \mathrm{AM}$ to $2 \mathrm{PM}$ on $3^{\text {rd }}$ and $4^{\text {th }}$ fully expanded leaves on the main shoot during the reproductive phase at 100days after sowing (Harper and Berkenkamp, 1975). Leaves should be dry without moisture or dew on them. All the leaves selected were fully sunlit prior to photosynthetic rate measurements .The photosynthetic radiations were between 1400 and $1800 \mu \mathrm{molm}^{-2} \mathrm{~s}^{-1}$. Water use efficiency was calculated as the ratio of photosynthesis per unit leaf area to transpiration.

The aboveground plant material in each plot was harvested by hand using a sickle, placed in sacks and allowed to air dry in the field. The dried samples were weighed to determine biological yield and the samples were threshed from which clean seeds were obtained and weighed for seed yield. Data analyses on photosynthetic characters were performed on means, which were averaged from the three measurements conducted on each leaf per plant per replicate. The character means for each replication were subjected to analysis of variance (ANOVA) for the factorial randomized complete block design. Means were compared using least significant differences at 5\% level. The correlation coefficients among different characters were also computed. All analyses were performed using SAS Institute, Carry, NC.

\section{RESULTS AND DISCUSSION}

Significant differences $(p<0.05)$ in Pn rates existed in the Brassica cultivars in the present investigation. The range of Pn was 31.7- 37.7 $\mu$ molm $^{-2} \mathrm{~s}^{-1}$ during the $1^{\text {st }}$ crop season while $30.5-37.5 \mu \mathrm{molm}^{-2} \mathrm{~s}^{-1}$ during $2^{\text {nd }}$ crop season.PBR210 possessed $35.2 \mu$ molm $^{-2} \mathrm{~s}^{-1}$ (B.juncea), $37.7 \mu \mathrm{molm}^{-2} \mathrm{~s}^{-1}$ in GSC6 (B. napus) and $31.7 \mu \mathrm{molm}^{-2} \mathrm{~s}^{-1}$ in PC5 during 2011-12.RLC1 had Pn of $37.5 \mu \mathrm{molm}^{-2} \mathrm{~s}$ ${ }^{-1}$,GSC6 of $35.0 \mu \mathrm{molm}^{-2} \mathrm{~s}^{-1}$ and PC5 $34.8 \mu \mathrm{molm}^{-2} \mathrm{~s}^{-1}$ during 2012-13.Although non-significant differences were found in Pn over the years of study (Table2). Average of two years indicated Pn of $36.1 \mu \mathrm{molm}^{-2} \mathrm{~s}^{-1}$ in RLC1, $36.3 \mu \mathrm{molm}^{-2} \mathrm{~s}^{-1}$ in GSC6 and $33.3 \mu \mathrm{molm}^{-2} \mathrm{~s}^{-}$ ${ }^{1}$ in PC5. Mean Pn rates were $1.5 \%$ higher during $1^{\text {st }}$ year. Interaction of $\mathrm{G}$ x Y for Pn was non-significant. RLC1 (B. juncea) and GSC6 (canola, B.napus) possessed highest Pn while cv.PBR210 possessed comparable $\mathrm{Pn}$ rates over the years. The observations at 100 days after sowing i.e. flowering and siliquae formation are consistent with the findings of other studies in which leaves were reported to be important sources of Pn up to flowering when stems and siliquae become more significant exporters of Pn (Uddin et al., 2012). Increase in Pn was due to increased chlorophyll content (Liu et al., 2012, Sharma et al., 2014). Further, genes associated with cell proliferation, photosynthesis and oil synthesis were unregulated which revealed photosynthesis contributed to increased seed weight and oil content. Cultivars differed significantly for $\mathrm{Cs}$ which was lowered during $2^{\text {nd }}$ crop season except in GSC6 (0.808).Cs was relatively higher in GSL1 and declined drastically over the years (Table 2). Average Cs was highest in PBR91 (0.682), GSC6 (0.767) and PC5 (0.707).Mean Cs was $14.1 \%$ higher during $1^{\text {st }}$ crop season. Re-evaluation of published data and genotypes with contrasting stomatal behavior (Tomimatsu and Tang, 2012) may help to quantify stomatal limitations on dynamic photosynthesis. Recently, Merilo et al. (2014) have shown the effects of different environmental factors on gs are non multiplicative, rarely predictable and strongly species dependent which contradicts often held

Table 5. Correlation coefficients for photosynthetic and related traits with seed yield in Brassica cultivars at 100 DAS.

\begin{tabular}{lcccccccc}
\hline Traits & Pn & Cs & Ci & Tr & Vpdl & Ct leaf & WUE & SY \\
\hline Pn & 1 & & & & & & & \\
Cs & $0.548^{* *}$ & 1 & & & & & & \\
Ci & -0.141 & $0.632^{* *}$ & 1 & & & & & \\
Tr & $0.506^{*}$ & $0.633^{* *}$ & $0.585^{* *}$ & 1 & & & & \\
Vpdl & -0.359 & $-0.921^{* *}$ & $-0.687^{* *}$ & -0.446 & 1 & & \\
Ct leaf & -0.184 & -0.368 & 0.0114 & 0.398 & 0.487 & 1 & \\
WUE & 0.462 & -0.131 & $-0.758^{* *}$ & $-0.526^{* *}$ & 0.143 & $-0.543^{* *}$ & 1 & \\
SY & 0.385 & 0.202 & 0.138 & -0.137 & -0.425 & -0.248 & 0.213 & 1 \\
\hline
\end{tabular}

$\mathrm{Pn}$ : net photosynthesis; Cs :stomatal conductance; $\mathrm{Ci}$ :internal $\mathrm{Co}_{2}$ concentration; $\mathrm{Tr}$ : Transpiration; Vpdl : vapour pressure deficit; Ct leaf : leaf temperature; WUE :water use efficiency; SY : seed yield. 

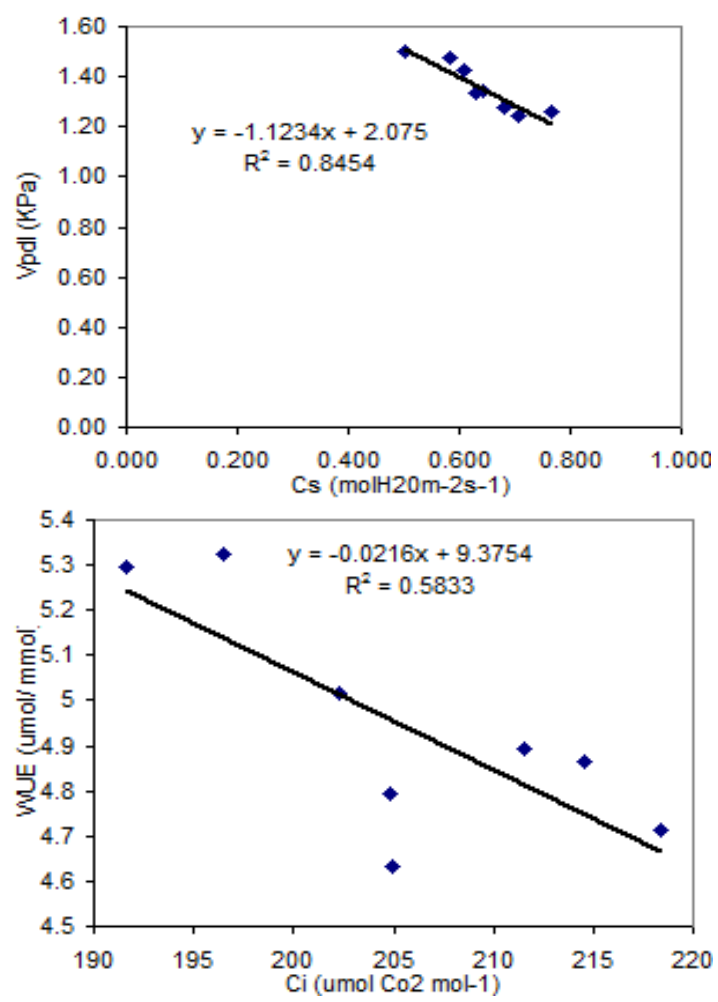
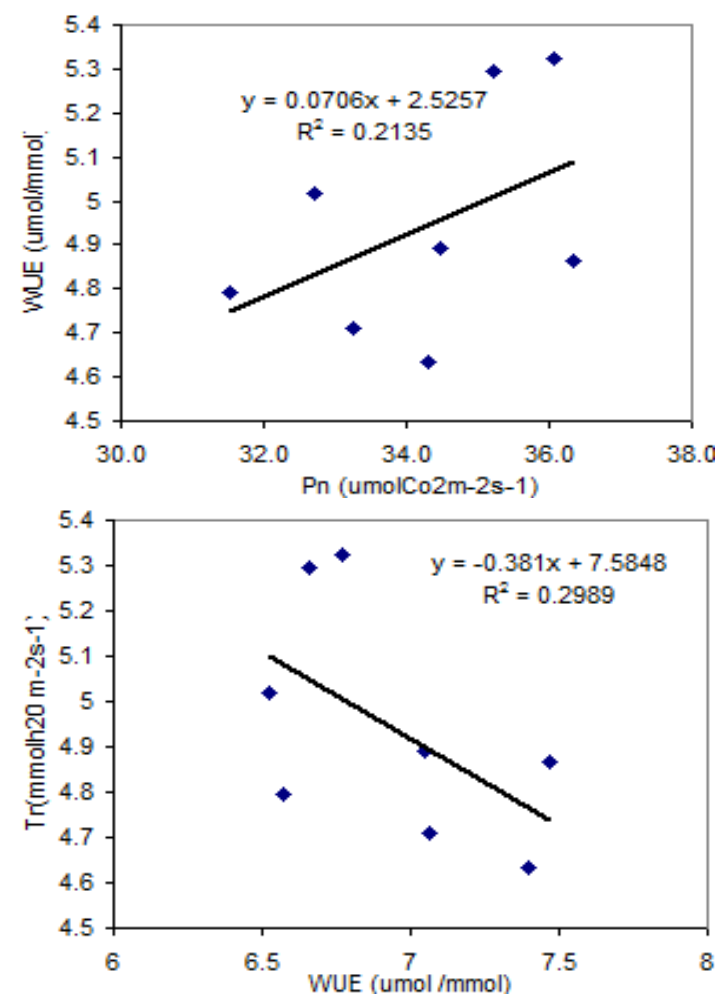

Fig. 2. Relationship between WUE and other traits of Pn at 100 DAS.

assumption that effects of single factors are multiplicative and uniform across species (Damour et al., 2010). Internal $\mathrm{CO}_{2}$ concentration was higher in PBR91, GSC6 and PC5 during 2011-12 while during $2^{\text {nd }}$ crop season again PBR91 in B.juncea and GSC 6 in $B$. napus registered higher $\mathrm{Ci}$. Genotypic average indicated higher $\mathrm{Ci}$ of $211.5 \mathrm{umolCO}_{2} \mathrm{~mol}^{-1}$ in PBR91, $214.6 \mathrm{umolCo}_{2} \mathrm{~mol}^{-1}$ in GSC6 and $218.4 \mathrm{umolCO}_{2} \mathrm{~mol}$ ${ }^{-1}$ in PC5.Mean $\mathrm{Ci}$ of the cultivars was $0.63 \%$ higher in 2012-13.Transpiration rates (Tr) were higher in PBR91 $\left(7.7 \mathrm{mmolm}^{-2} \mathrm{~s}^{-1}\right)$, GSC5 $\left(8.3 \mathrm{mmolm}^{-2} \mathrm{~s}^{-1}\right)$ and 7.2 mmolm $^{-2} \mathrm{~s}^{-1}$ in PC5 during 2011-12 while PBR210 had Tr of $6.6 \mathrm{mmolm}^{-2} \mathrm{~s}^{-1}$ and GSC6 $\left(7.4 \mathrm{mmolm}^{-2} \mathrm{~s}^{-1}\right)$ during 2012-13.Avearge rate of Tr were comparable in PBR210 and RLC1 and higher in PBR91amongst the B.juncea cultivars. Similarly, comparable $\operatorname{Tr}$ was recorded in GSC6 and GSC5and also in GSL1 and Hyola PAC401 amongst the B.napus cultivars. However, mean of the years indicated $\mathrm{Tr}$ higher by $12.1 \%$ in the $2^{\text {nd }}$ crop season. This could be ascribed to wet year and erratic rainfalls. Amongst the cultivars $\mathrm{Tr}$ were comparable in PBR210 and GSC6 over the years. Vapour pressure differential (Vpdl) was higher during $2^{\text {nd }}$ crop season except in PBR210, GSC5 and HyolaPAC401 (Table 3). Average Vpdl was $1.46 \mathrm{kPa}$ in PBR210, $1.58 \mathrm{kPa}$ in Hyola and least $1.32 \mathrm{kPa}$ in PC5. Genotypes and environment did not register significant differences for this trait however, interaction between $\mathrm{G} \times \mathrm{Y}$ were significant .Mean Vpdl was $6.2 \%$ higher due to higher rainfall. Elevated Vpdl lowers gs to variable extent, which might decrease $\mathrm{Ci}$ affecting both carboxylation rates and Rubisco activation in fluctuating irradiance (Kaiser et al., 2014) Leaf temperature varied significantly within the cultivars. Only $3.5 \%$ higher mean temperature was recorded during 2011-12 than 2012-13. Average leaf temperature was comparable in PBR210 and RLC1, GSC6, HyolaPAC401 and PC5. Leaf temperature and $\mathrm{CO}_{2}$ affect rates of dynamic photosynthesis more strongly than Vpdl (Sharma et al., 2012; Kaiser et al., 2014).

The differences in Tr or WUE on the leaf were significant among different cultivar of Brassica spp. A range of 4.8 - $5.8 \mu \mathrm{molCO}_{2} / \mathrm{mmol} \mathrm{H}_{2} \mathrm{O}$ in WUE (2012-13) have been recorded in the present investigation. Mean WUE of the cultivars was $5.6 \%$ lower than the $2^{\text {nd }}$ crop season. Lower $\operatorname{Tr}$ and more water retention therefore higher WUE was recorded in the different cultivars during 2012-13 and impact of environment was also significant (Table 4).Among the B. juncea cultivars, lower average transpirational rates were related to higher WUE in PBR210 and RLC1.GSL1, a non canola cultivar had lowest $\mathrm{Tr}$ of $6.5 \mathrm{mmolm}^{-2} \mathrm{~s}^{-1}$ and high WUE of $5.44 \mu \mathrm{molCO}_{2} / \mathrm{mmol} \mathrm{H}_{2} \mathrm{O}$ amongst the B.napus cultivars. WUE was higher in GSC6 than GSC5 though both the cultivars reported comparable Tr. Hyola PAC401, a hybrid canola possessed average $\mathrm{Tr}$ of $6.6 \mathrm{mmolm}^{-2} \mathrm{~s}^{-1}$ and WUE of $5.21 \mu \mathrm{mol}$ $\mathrm{CO}_{2} / \mathrm{mmol} \mathrm{H}_{2} \mathrm{O}$. These results indicated that water was more effectively utilized for assimilate production during the reproductive phase and in this sense the differences in seed yield amongst the cultivars were related to $\mathrm{Tr}$ and WUE. Linear regression between different components of net photosynthesis indicated differential association among them (Figs. 1 and 2). 
Overall mean Pn and WUE was higher in B.juncea than B.napus cultivars. PC5 (B. carinata) possessed WUE comparable to GSC5, a canola cultivar. Mean Pn was higher by $1.5 \%$, Cs $14.1 \%$, Tr $12.1 \%$ and leaf temperature by $3.5 \%$ during 2011-12 while $\mathrm{Ci}$,Vpdl and WUE by $0.63 \%, 6.2 \%$ and $5.6 \%$ in the second year of study. Cultivars differed significantly for photosynthetic traits except Vpdl. Environment had a profound impact on WUE while interactions ( $\mathrm{G} \times \mathrm{Y})$ were significant $(p<0.05)$ for all the studied photosynthetic traits except Pn. The sub processes of dynamic photosynthesis are affected differently by climate: the activation state of RuBP-regenration is only influenced by temperature while the activation state is directly affected by $\left[\mathrm{CO}_{2}\right]$ and temperature, and indirectly (via Ci) Vpdl (Kaiser et al., 2014).

Coefficient of correlation between photosynthetic traits and seed yield represented as mean of the two years are recorded in Table 5. Highly significant correlation existed between $\mathrm{Cs}$ and $\mathrm{Pn}\left(0.548^{* *}\right), \mathrm{Ci}$ and $\mathrm{Cs}$ $(0.632 * *), \operatorname{Tr}$ and $\mathrm{Pn}(0.506), \operatorname{Tr}$ and $\mathrm{Ci}\left(0.585^{* *}\right)$. Vpdl showed highly negative correlation with Cs $(-0.921 * *)$ but positive association with $\mathrm{Ci}$ $(0.687 * *)$.WUE was negatively correlated with $\mathrm{Ci}$ $\left(-0.758^{* *}\right)$, Tr $\left(-0.526^{*}\right)$ and ct $\left(-0.543^{*}\right)$. Seed yield was positively correlated with Pn (0.378) ,Cs (0.202), WUE (0.213) though the magnitude of association was low indicating variations were due to genetic differences not environmentally affected as the interaction between $G \times$ Y were significant only for water use efficiency in the present investigation. However, correlation between seed yield and single leaf photosynthesis were not observed by Congo and McVetty (2001) in B.napus.

\section{Conclusion}

Correlation between seed yield and leaf photosynthetic rates has been observed for the first time in Brassicas. High yielding cultivars displayed high net photosynthetic rates, utilized water more efficiently at flowering and early siliquae formation stage, and produced relatively higher seed yield, suggesting the importance of leaves/source which is not limiting during this phase. Cultivars in the present study exhibited indeterminate growth habits and the measurements were conducted only up to early siliquae formation which eliminated any assessment for siliqua photosynthesis in accounting for the potential differences in the traits studied. Therefore incorporation of photosynthesis by developing siliquae could improve the assessment of physiological traits in oilseeds in the future.

\section{REFERENCES}

Chongo, G. and McVetty, P.B.E. (2001). Relationship of physiological characters to yield parameters in oilseed rape (Brassica napus L.) Canadian Journal Plant Science, 81:1-6.

Damour, G., Simonneau, T., Cochard, H. and Urban, L. (2010). An overview of models of stomatal conductance at the leaf level. Plant Cell and Environment, 33:1419-1438.

Harper, F. R. and Berkenkamp, B.(1975). Revised growth stage key for Brassica campestris and B. napus. Canadian Journal of Plant Sciences,55: 657-658.

Kaiser, E., Morales, A., Harbinson, J., Kromdijk, J. Havelock, E. and Marcelis, L.F.M. (2014). Dynamic photosynthesis in different environmental conditions. Journal of Experiment Botanical Advances Access, 1-12. doi:10.1093/ jxb / eru406.

Kumar, V. and Chopra, A.K. (2014). Ferti-irrigational response of hybrid cultivar of Indian mustard (Brassica juncea L.) to distillery effluent in two seasons. Analytical Chemistry Letters, 4(3): 190-206.

Lowlor, D.W. (1995). Photosynthesis, productivity and environment. Journal Experimental Botany, 46: 1449-1461.

Liu, J. Hua,W. Yang, H.L., Zhan ,G. M., Li, R. J., Deng, L. B., Wang ,X.F., Liu, G.H. and Wang, H.Z. (2012). The BnGRF2 gene (GRF2-like gene from Brassica napus) enhances seed oil production through regulating cell number and plant photosynthesis. Journal of Experiment Botanical Advances Access, 1-14. doi:10.1093/jxb/ers066.

Merilo, E., Joesaar, I.,Brosche, M., and Kollist, H. (2014). To open or to close species -specific stomatal responses to simultaneously applied opposing environmental factors. New Phytologist , 202:499-508.

Richards, R.A. (2000). Selectable traits to increase crop photosynthesis and yield of grain crops. Journal of Experimental Botany, 51: 447-458.

Sharma, P., Sardana, V. and Banga,S.S.(2014). Physiological traits and dry matter partitioning under low light stress in identified genotypes of Indian mustard (Brassica juncea). In $2^{\text {nd }}$ National Brassica Conference on Brassicas for Addressing Edible Oil and Nutritional Security held at PunjabAgricultural University Ludhiana during February 14-16.

Sharma, P., Sardana, V. and Banga,S.S.(2012). Shading effect on photosynthesis, dry matter accumulation and yield of Indian mustard (Brassica juncea L.) genotypes. In International Conference on Sustainable Agriculture for Food and Livelihood Security held at Punjab Agricultural University, Ludhiana on November, 27-29.

Tomimatsu, H., and Tang, Y. (2012). Elevated $\mathrm{CO}_{2}$ differentially affects photosynthetic induction response in two Populus species with different stomatal behavior. Oecologia, 169: 869-878.

Uddin,M.A., Ullah,M.A.,Sultana,F.,Rahman,K.M.,and Rahman, M.Z. (2012). Evaluation of some Rapeseed Mutants $\mathrm{B}$ on Morpho-Physiological, Biochemical and yield Attributes. Journal Environmental Sciences and Natural Research, 5 (2):281-285. 